\title{
PROGRESSOS NA VITICULTURA BRASILEIRA ${ }^{1}$
}

\author{
UMBERTO ALMEIDA CAMARGO ${ }^{2 *}$, JORGE TONIETTO ${ }^{3}$, ALEXANDRE HOFFMANN ${ }^{3}$
}

RESUMO - A viticultura brasileira nasceu com a chegada dos colonizadores portugueses, tornando-se uma atividade comercial a partir do início do século XX. Houve absoluto predomínio do cultivo de uvas americanas até meados do século XX, quando se iniciou o plantio de videiras europeias. Até a década de 1960, a viticultura brasileira ficou limitada às regiões Sul e Sudeste. A partir daí, a uva alastrou-se como alternativa econômica em diversas regiões tropicais do País e ganhou nova dimensão nas zonas temperadas de cultivo. Atualmente, a área vitícola brasileira situa-se ao redor de 83.700 ha, com uma produção anual oscilando entre 1.300.000 e 1.400.000 toneladas. Destacam-se, pelo volume de produção, os Estados do Rio Grande do Sul, São Paulo, Pernambuco, Paraná, Bahia, Santa Catarina e Minas Gerais. A grande maioria das uvas e seus derivados são consumidos no mercado interno. O suco de uva concentrado e a uva de mesa são os principais produtos de exportação. A diversidade é a marca da viticultura brasileira: são diferentes condições ambientais, variados sistemas de cultivo e recursos genéticos com ampla variabilidade. Neste trabalho, é traçado o perfil da viticultura brasileira e são apresentados os principais avanços tecnológicos obtidos nas últimas décadas. Entre outros tópicos, destacam-se a criação de novas cultivares, o desenvolvimento de técnicas e sistemas de manejo da videira - especialmente para as zonas tropicais e o desenvolvimento de sistemas de certificação de produtos vitivinícolas.

Termos para Indexação: Tecnologia vitícola, uva de mesa, vinho, suco de uva, cultivares, manejo do vinhedo, certificação de produtos vitivinícolas.

\section{ADVANCES IN GRAPE CULTURE IN BRAZIL}

\begin{abstract}
Viticulture was introduced in Brazil by Portuguese settlers in the 16th century, becoming a commercial activity in the south of the country, after 1875. Vineyards of American grapes were predominant until the middle of 20th century, when some Vitis vinifera varieties were planted. For a long time Brazilian viticulture was limited to the southern and southeastern states as a typical temperate culture. In the 1960's viticulture was expanded into the tropical regions of Brazil, while there was also an important icrease in the grape growing area in the traditional temperate zones. Nowadays the grape growing area in Brazil is around 83.700 ha, producing between 1.300 and 1.400 thousand tons. In Brazil, grape production is concentrated at the states of Rio Grande do Sul, São Paulo, Pernambuco, Paraná, Bahia, Santa Catarina and Minas Gerais. Most of the grape and its products (wine and juice) are consumed by Brazilian market. Concentrated grape juice and fresh grapes are the main products exported. Diversity is the main characteristic of Brazilian viticulture: there is a wide genetic diversity on vineyards and grapes are cultivated in different environments, using several production systems and cultural practices. This paper presents a general view of Brazilian viticulture and the main technological and innovation advances obtained in grape culture in the last decades. Emphasis is on new cultivars, on new techniques and cultural practices used - mostly on tropical viticulture - and on systems of certification for wines and other products from grapes.
\end{abstract}

Index Terms: Viticulture technology, table grape, wine, grape juice, cultivars, vineyard management, grape products certification.

\footnotetext{
${ }^{1}$ Palestra Sinfruit 098 - Simpósio Internacional de Fruticultura - Avanços na Fruticultura (17 a 21 Outubro)

${ }^{2}$ Vino Vitis Consultoria Ltda. Rua Agnaldo da Silva Leal, 141, apto. 301, CEP 95700-000 Bento Gonçalves-RS, Brasil. E-mail: umberto.camargo@gmail.com*Autor para contato

${ }^{3}$ Embrapa Uva e Vinho. Rua Livramento, 515, CEP 95700-000 Bento Gonçalves-RS, Brasil. E-mail: tonietto@cnpuv.embrapa.br, hoffmann@cnpuv.embrapa.br
} 


\section{PANORAMA GERAL DA VITICULTURA BRASILEIRA}

A viticultura brasileira apresenta grande diversidade. A atividade ocupa uma área de aproximadamente 83.700 hectares, com uma produção anual variando entre 1.300 e $1.400 \mathrm{mil}$ toneladas. No ano de 2010, aproximadamente $57 \%$ da produção total foi comercializada como uvas de mesa e $43 \%$ destinada ao processamento de vinhos e suco de uva (MELLO, 2011). Há uma grande variabilidade no material genético utilizado. São mais de 120 cultivares de Vitis vinifera e mais de 40 cultivares de uvas americanas, incluindo castas de Vitis labrusca, Vitis bourquina e de híbridas interespecíficas.

A cultura está difundida desde o Rio Grande do Sul, a $31^{\circ} \mathrm{S}$ de latitude, até o Rio Grande do Norte e Ceará, a $05^{\circ} \mathrm{S}$ de latitude. A variação de altitude também é grande, havendo considerável diversidade ambiental entre as zonas de produção, incluindo regiões de clima temperado, subtropical e tropical. A viticultura de clima temperado caracteriza-se por um ciclo anual, seguido de um período de dormência induzido pelas baixas temperaturas do inverno. É a viticultura tradicional no Sul e em regiões de altitude do Sudeste do Brasil, nos Estados do Rio Grande do Sul, Santa Catarina, Paraná, São Paulo e Minas Gerais. A viticultura subtropical é praticada em regiões de invernos amenos e curtos, porém sujeitos à ocorrência de geadas. Nessas condições, a videira tem um período de dormência natural em junho e julho, e pode ser manejada da maneira tradicional, com um ciclo por ano. Todavia, com a utilização de sistemas especiais de manejo, são realizados dois ciclos vegetativos, com a obtenção de duas colheitas por ano. A viticultura subtropical é importante no norte do Paraná e no leste de São Paulo, onde são adotados sistemas peculiares de manejo da videira.

A viticultura tropical é típica de regiões onde as temperaturas mínimas não são suficientemente baixas para induzir a videira à dormência. A videira cresce continuamente e, com o uso de tecnologia apropriada, é possível a obtenção de duas ou mais colheitas por ano, no mesmo vinhedo. A época de colheita pode ser programada para qualquer dia do ano. Os principais polos de viticultura tropical no Brasil são o Vale do Submédio São Francisco, o noroeste Paulista e o norte de Minas Gerais. Nos últimos anos, a viticultura tropical expandiu-se por vários outros Estados, como Espírito Santo, Mato Grosso do Sul, Mato Grosso, Goiás, Rondônia, Ceará e Piauí.

\section{PROGRESSOS DA VITICULTURA BRASILEIRA}

Até o final dos anos de 1950, a viticultura comercial brasileira estava restrita aos três Estados do Sul e regiões leste de São Paulo e sul de Minas Gerais. A partir daí, houve uma grande ampliação da fronteira vitícola, com o plantio de uvas no Vale do Submédio São Francisco, seguindo-se as regiões norte do Paraná, noroeste de São Paulo e norte de Minas Gerais. Nas regiões tradicionais, os sistemas de produção foram sendo modificados ao longo dos anos, em função das oportunidades e exigências do mercado. A pesquisa deu suporte ao empreendedorismo do viticultor brasileiro, aportando tecnologias sem as quais não seria possível atingir o atual nível de desenvolvimento do setor. Como exemplos, podem ser citadas a seleção de clones e novas cultivares adaptadas às diferentes regiões, a definição de diferentes tecnologias de manejo especialmente para as regiões tropicais e subtropicais e a certificação de produtos vitivinícolas, como produção integrada, indicações geográficas e produção orgânica.

\section{Progressos em Cultivares}

Registros históricos indicam que a evolução do quadro varietal foi permanente na viticultura brasileira (GOBBATO; MARTINS, 1938; DIAS, 1959; SOUSA, 1959). No Sul do País, a viticultura consolidou-se com uvas americanas, predominantemente com a cultivar Isabel. Depois, outras uvas americanas ganharam grande espaço, como Herbemont, Seibel 2, Niágara Branca, Niágara Rosada e Jacquez. Nos anos de 1970, outras uvas americanas, como Seyve Villard 5276 e Couderc 13, deram suporte à expansão do mercado de vinhos brancos, enquanto as cultivares Bordô e Concord tiveram grande aumento de área plantada para a produção de vinhos tintos e suco de uva, respectivamente. No Estado de São Paulo, a cultivar Isabel, plantada inicialmente, deu espaço para a Niágara Rosada, como uva de mesa, e para as cvs. Seibel 2 e Máximo (IAC 138-22) para a elaboração de vinho.

A difusão de castas viníferas no Rio Grande do Sul iniciou-se efetivamente na década de 1950, com o plantio das cultivares italianas Barbera, Bonarda, Peverella, Marzemino, Trebbiano e outras. Logo em seguida, entraram em cultivo Cabernet Franc, Merlot e Riesling Itálico para a produção dos primeiros vinhos varietais. A maioria destas cultivares, nos anos de 1970 e 1980, foi substituída por castas 
de origem francesa, como Cabernet Sauvignon, Tannat, Sémillon e Chardonnay, entre outras. Mais recentemente, no Sul entraram em cultivo uvas como Pinot Noir, Tempranillo, Sauvignon Blanc, Moscato Giallo e Viognier. Já no Vale do São Francisco, a produção de vinhos consolidou-se com as cultivares Syrah, Alicante Bouschet, Chenin Blanc e Moscato Canelli. Atualmente, novas alternativas estão em expansão na região como Tempranillo, Petit Verdot, Touriga Nacional, Grenache e Verdelho, entre outras.

Em relação às uvas finas de mesa, o quadro varietal tem sido mais estável, com a cultivar Itália mantendo presença marcante em todas as áreas de produção. Todavia, houve diversificação da produção, inicialmente com as cultivares coloridas, derivadas da cv. Itália, Ruby, Benitaka e Brasil. No Vale do São Francisco, a cv. Piratininga teve área expressiva na década de 1980, mas foi substituída pela cv. Red Globe, que se difundiu rapidamente na região, na década de 1990. Porém, a cv. Red Globe, devido à sua suscetibilidade ao cancro bacteriano, sofreu drástica redução da área plantada a partir de 1996, sendo substituída pela cv. Benitaka. A partir do ano de 2000, as cultivares de uvas sem sementes Festival (Superior ou Sugraone), Thompson Seedless e Crimson Seedless tiveram extensas áreas plantadas. Nas demais regiões produtoras de uvas de mesa, as cultivares do grupo Itália continuam sendo predominantes.

Como uva americana de mesa, a Niágara Rosada é praticamente a única alternativa, com presença marcante nos vinhedos de todas as regiões produtoras. É uma uva de fácil manejo no campo e de grande aceitação no mercado.

Referente aos porta-enxertos, diversas cultivares foram utilizadas no Rio Grande do Sul. Até a década de 1970, os mais utilizados foram Rupestris Du Lot, Riparia Gloire de Montpellier, 101-14 Mgt, Solferino, Kober 5BB, Golia e Téléki $8 \mathrm{~B}$. No final dos anos de 1970, outros porta-enxertos foram introduzidos,destacando-se SO4, R 99 e R 110. O SO4 teve rápida e significativa difusão, porém, devido à sua sensibilidade à fusariose, logo caiu em desuso, sendo substituído pelo Paulsen 1103, que é resistente à doença (CAMARGO; DIAS, 1986). Assim, desde os anos de 1990, o Paulsen 1103 é o porta-enxerto predominante na implantação de novos vinhedos no Sul do Brasil. Recentemente, vem sendo plantado em algumas áreas de Santa Catarina, Rio Grande do Sul e Paraná o porta-enxerto 043-43, um híbrido de Vitis rotundifolia resistente à pérolada-terra. Todavia, sua difusão é restrita, tendo em vista sua sensibilidade a fungos de solo que causam apodrecimento das raízes. Para as uvas finas de mesa, no Paraná e São Paulo, o porta-enxerto 420 A é predominante, enquanto para a Niágara Rosada o 106-8 Mgt, mais conhecido por Traviú, é o mais utilizado. Nas regiões tropicais, os porta-enxertos 'IAC 313 Tropical', 'IAC 572' e 'IAC 766 Campinas' são os mais difundidos. O IAC 313 foi a base do desenvolvimento da viticultura tropical no Vale do São Francisco, Jales e Pirapora. A partir da década de 1990, entretanto, a maioria dos novos vinhedos, em todas as áreas tropicais do Brasil, foi implantada com o IAC 572. Já o IAC 766 alcançou maior difusão no norte do Paraná e no leste de São Paulo, mas também é cultivado em regiões tropicais. Para as uvas sem sementes, no Vale do São Francisco, são bastante usados Harmony, Salt Creek e SO4.

No caso de uvas americanas e híbridas para processamento, diversas novas cultivares estão sendo difundidas nos vários polos de produção, algumas com perspectivas de grande expansão. Destacam-se as brancas Moscato Embrapa e BRS Lorena, ambas já com volume significativo de produção no Rio Grande do Sul e em expansão nos Estados de Santa Catarina, Paraná, São Paulo, Minas Gerais e Espírito Santo. Entre as tintas, destacam-se BRS Rúbea, BRS Cora, BRS Violeta, BRS Carmem, Isabel Precoce e Concord Clone 30, usadas prioritariamente para suco, mas que também podem ser usadas para vinho. Dentre estas, Isabel Precoce, BRS Cora e BRS Violeta são a base para o desenvolvimento dos polos de produção de suco de uva nos Estados do Espírito Santo, Goiás, Mato Grosso e Vale do São Francisco (CAMARGO, 2008).

\section{Progressos em Técnicas de Cultivo}

A viticultura brasileira apresentou uma evolução muito grande nos últimos 50 anos. Partindo da produção tradicional de algumas cultivares de uvas americanas, restrita ao sistema de manejo com um ciclo por ano, avançou para novas regiões, diversificando em cultivares e em sistemas de produção. Técnicas modernas de diagnose e monitoramento nutricional, sistemas de irrigação e fertirrigação, sistemas de monitoramento e controle sanitário foram incorporados aos sistemas de produção das diferentes regiões em maior ou menor grau. Na produção de uvas de mesa, algumas regiões investiram no cultivo protegido com o uso de tela ou cobertura plástica. Todavia, algumas técnicas de manejo da videira foram especialmente relevantes para a expansão da área cultivada e para a qualificação da produção de uvas no Brasil.

$\mathrm{O}$ uso de substâncias para induzir à brotação, inicialmente a cálcio-cianamida e, depois, a cianamida hidrogenada, foi um avanço de grande 
significado. Além de promover a brotação, o uso destes produtos propicia uniformidade na brotação e, por consequência, facilita a execução das práticas de manejo da copa e da produção, como poda verde, aplicação de reguladores de crescimento e colheita. No caso da viticultura de clima subtropical, com a indução da brotação, foi possível estabelecer sistemas de produção com duas colheitas anuais.

A definição do sistema de manejo da copa para promover a indução e a diferenciação floral em uvas sem sementes teve grande impacto na produção de uvas de mesa. Este sistema tornou possível a produção comercial de uvas sem sementes no Vale do São Francisco, o que alavancou as exportações brasileiras de uva de mesa a partir do ano de 2000. No que concerne às uvas americanas de mesa, o sistema de produção da Niágara Rosada em regiões tropicais (MAIA; KUHN, 2001) determinou a oferta desta uva no mercado ao longo do ano.

A produção de vinhos de alta qualidade em zonas tropicais ganhou perspectiva com a estratégia de produção da uva em regiões de altitude, com duas podas anuais e apenas uma colheita. A colheita é programada para o período de temperaturas mais baixas, coincidente com o período de estiagem, proporcionando uvas de excelente qualidade (AMORIM et al., 2005; MOTA et al., 2010).

A mecanização dos vinhedos ganhou impulso nos últimos anos. Os pequenos produtores do Rio Grande do Sul sistematizaram seus vinhedos de encostas para a pulverização mecanizada. Os vinhedos de castas finas para vinho estão sendo implantados em sistema de condução em espaldeiras, adaptados à mecanização da maioria das práticas culturais, incluindo poda, poda verde e colheita, além das pulverizações. A colheita mecânica da uva já começou a ser praticada na região da Campanha do Rio Grande do Sul. Também foram implantados vinhedos em outros sistemas de condução, visando a facilitar os trabalhos, reduzir a necessidade de mão de obra e, em alguns casos, a aumentar a produtividade, como o Y para uvas sem sementes no Vale do São Francisco, para a Niágara Rosada em São Paulo e para uvas de vinho no Sul. O sistema GDC e a espaldeira com duplo cordão vêm sendo usados para uvas de suco no norte do Paraná, adaptados ao uso de máquinas e equipamentos maiores, usados, também, para outras culturas nas propriedades.

\section{Progressos na Certificação de Produtos Vitivinícolas}

As exigências do mercado por produtos de qualidade comprovada, oriundos de processos produtivos que valorizam a origem dos produtos, bem como o comprometimento com a segurança alimentar e com a proteção ambiental, são cada vez maiores, tornando indispensável a adoção de sistemas de certificação da produção para competir em mercados mais exigentes. O setor vitivinícola brasileiro avançou significativamente nos últimos anos através da produção integrada de uvas finas de mesa, da definição das primeiras indicações geográficas para a produção de vinhos finos e da produção orgânica de uva, vinho e suco de uva.

\section{Produção Integrada de Uva}

O primeiro programa oficial de certificação de frutas no Brasil foi o de Produção Integrada (PI), regulamentado em 2001. Em 2003, foi regulamentado o programa de PI Uva no Vale do Submédio São Francisco. O sistema de Produção Integrada reúne normativas e procedimentos que asseguram a qualidade da fruta, a aplicação de procedimentos técnicos coerentes com o respeito ao ambiente, à legislação trabalhista e à saúde do consumidor. Tais normas abrangem desde a implantação do pomar, procedimentos de manejo, técnicas de pós-colheita até a expedição e distribuição da fruta, assegurando o registro e o resgate das informações em qualquer uma destas etapas. O PI Uva no Vale do Submédio São Francisco chegou a 4.000 hectares, dando um suporte importante para a exportação de uvas de mesa da região (OLIVEIRA et al., 2009). Derivado do trabalho com a PI, houve um significativo aprimoramento do sistema de produção de uvas de mesa, com a racionalização do uso de insumos e uma melhoria substancial na organização da informação por meio dos cadernos de campo. Tais melhorias foram incorporadas ao sistema e, mesmo nas empresas que não certificam, há adoção destes aprimoramentos. Igualmente, os conhecimentos resultantes da prática da PI subsidiaram a adesão a outros protocolos privados de certificação de qualidade que vêm sendo adotados pelos produtores do Vale do São Francisco para atendimento de alguns mercados, como é o caso da GLOBALGAP e do sistema de Análise de Perigos e Pontos Críticos de Controle (APPCC).

No segmento de uvas para processamento, o ingresso nas ações de PI deu-se mais tardiamente, na medida em que a percepção de eventuais barreiras não tarifárias cresceu com a evolução do acesso de vinhos e sucos brasileiros no mercado externo. As primeiras ações de definição das normativas técnicas e elaboração de cadernos de campo foram feitas pela Embrapa Semiárido no Vale do São Francisco, em parceria com produtores da região. A partir de 2010, a Embrapa Uva e Vinho iniciou ações de pesquisa 
e transferência de tecnologia com uvas para vinhos finos e para sucos no Rio Grande do Sul, em parceria com várias empresas e produtores de vários estados (RS, SC, PR, PE, BA).

\section{Indicações Geográficas de Vinhos Finos e Espumantes}

Os anos de 1990 marcam um novo período na produção de vinhos finos com o início do desenvolvimento de indicações geográficas, a partir de um trabalho da Embrapa Uva e Vinho, estimulando a valorização dos vinhos nacionais através deste instrumento de propriedade industrial (TONIETTO, 1993), cujo amparo legal veio com a entrada em vigor da Lei de Propriedade Industrial (LPI) - número 9.279 (BRASIL, 1996), possibilitando o reconhecimento de proteção jurídica de indicações geográficas brasileiras, seja como Indicação de Procedência, seja como Denominação de Origem (INPI, 2000).

Em 1995, pequenos produtores vitivinícolas da atual Indicação de Procedência Vale dos Vinhedos, na Serra Gaúcha, fundaram a Associação dos Produtores de Vinhos Finos do Vale dos Vinhedos (Aprovale) e iniciaram o desenvolvimento de uma indicação geográfica (TONIETTO, 2006).

A IP Vale dos Vinhedos foi reconhecida em 2002 pelo Instituto Nacional da Propriedade Industrial - INPI, tornando-se a primeira IG brasileira. Compreende uma área geográfica delimitada de 81,23 $\mathrm{km}^{2}$ e protege produtos vitivinícolas, como os vinhos finos e espumantes, dentre outros. Atualmente, o Vale dos Vinhedos, através da Aprovale, está com pedido de reconhecimento junto ao INPI da primeira Denominação de Origem de vinhos do Brasil.

Os resultados positivos evidenciados na produção vitivinícola, o crescimento do enoturismo e o desenvolvimento territorial no âmbito da IP Vale dos Vinhedos estimularam outros produtores a se organizarem em associações, visando ao reconhecimento de indicações geográficas.

Em 2010, foi reconhecida a IP Pinto Bandeira, segunda IG brasileira de vinhos, sendo que outros projetos de desenvolvimento de IG estão em andamento (TONIETTO; ZANUS, 2007): Monte Belo (Aprobelo), Altos Montes (Apromontes), Farroupilha (Afavin) e Submédio São Francisco (Vinhovasf). Outros projetos começam a ser estruturados, como na região da Campanha, bem como outras regiões também deverão implementar políticas de organização e valorização da produção na modalidade de IG (Serra do Sudeste, Planalto Catarinense, Campos de Cima da Serra).

Pode-se verificar que as indicações geográficas de vinhos passam a se constituir em elemento de inovação e de política setorial para ampliar a competitividade da produção de vinhos brasileiros.

\section{Indicação de Procedência dos Vinhos de Mesa Goethe}

A vitivinicultura da região carbonífera de Santa Catarina, cujo polo de referência é Urussanga, consolidou-se com base na uva Goethe, uma híbrida interespecífica com a qual é elaborado um vinho branco de mesa, típico da região. A Associação dos Produtores da Uva e do Vinho Goethe - Progoethe, com o apoio de diversas instituições, como SebraeSC, Fapesc, Epagri e UFSC, implementou um programa de ações com diversos projetos nas áreas técnica e promocional, cujo objetivo é o de qualificar de forma crescente os vinhos de mesa Goethe. Atualmente, o principal objetivo da Progoethe está relacionado com a implantação da Indicação de Procedência dos Vinhos Goethe, cujo processo se encontra tramitando junto ao Instituto Nacional de Propriedade Industrial - INPI.

\section{Produção Orgânica de Uva}

A produção orgânica de uva no Brasil ainda é pequena, e as informações a respeito são esparsas e pouco consistentes. De qualquer forma, sabe-se que existem iniciativas de produção orgânica de uva em praticamente todos os estados produtores. No caso de produtos voltados ao mercado interno, como é o caso da uva orgânica, grande parte da produção provém da agricultura familiar, cuja comercialização ocorre em feiras, diretamente ao consumidor. Isto tem dificultado o controle estatístico da produção. Entretanto, com a implementação do selo oficial de avaliação da conformidade orgânica, o credenciamento de certificadoras e o cadastro de produtores orgânicos no MAPA, a produção e a comercialização de uva orgânica e seus derivados, assim como de outros produtos orgânicos, deverão crescer de forma organizada e com melhor controle em todas as etapas. No Rio Grande do Sul, que é o maior produtor de uvas do Brasil, a Emater-RS tem acompanhado a produção orgânica de uvas e, de acordo com dados extraoficiais levantados, a área de produção de uva orgânica no Estado passou de 90 ha, em 2005, para 517 ha, em 2011. No mesmo período, o incremento da produção passou de 1.000 t para $7.000 \mathrm{t}$, sendo que grande parte desta uva foi destinada à produção de suco de uva e vinhos. 


\section{REFERÊNCIAS}

AMORIM, D. A.; FAVERO, A. C.; REGINA, M. A. Produção extemporânea da videira, cv. Syrah, nas condições do sul de Minas Gerais. Revista Brasileira de Fruticultura, Jaboticabal, v. 27, n. 2, p. 327-331, 2005.

BRASIL. Lei n 9.279, de 14 de maio de 1996 - Lei da Propriedade Industrial. Brasília: Ministério do Desenvolvimento, Indústria e Comércio Exterior, 1996.

CAMARGO, U. A. Impacto das cultivares brasileiras de uva no mercado interno e potencial no mercado internacional In: In: CONGRESSO BRASILEIRO DE VITICULTURA E ENOLOGIA, 12., 2008, Bento Gonçalves. Anais... Bento Gonçalves: Embrapa Uva e Vinho, 2008. p. 37-42.

CAMARGO, U. A.; DIAS, M. F. Identificação ampelográfica de videiras americanas e híbridas cultivadas na MRH 311. Bento Gonçalves: Embrapa-Centro Nacional de Pesquisa de Uva e Vinho, 1986. 40p. (Circular Técnica, 12).

DIAS, M. F. A variedade na renovação dos vinhedos Riograndenses. Agronomia Sulriograndense, Porto Alegre, v. 4, p. 43-55, 1959.

GOBBATO, C.; MARTINS, J. W. Subsídios sobre a adaptação, ao nosso meio, de algumas castas produtoras de vinho. Porto Alegre: Secretaria de Estado dos Negócios da Agricultura, Indústria e Comércio, 1938. 13 p. (Boletim, 63).

INSTITUTO NACIONAL DE PROPRIEDADE INDUSTRIAL. Resolução $\mathbf{n}^{0} \mathbf{0 7 5} / \mathbf{2 0 0 0}$, de 28 de novembro de 2000 - Estabelece as condições para o registro das indicações geográficas. Rio de Janeiro: INPI, 2000. 7 p.

MAIA, J. D. G.; KUHN, G. B. (Ed.). Cultivo da Niágara Rosada em áreas tropicais do Brasil. Bento Gonçalves: Embrapa Uva e Vinho, 2001. 72 p.

MELLO, L. M. R. Vitiviniculura brasileira: panorama 2010. Disponível em: <http://www. cnpuv.embrapa.br/publica/artigos/prodvit2010.pdf $>$. Acesso em: 04 jul. 2011.
MOTA, R. V.; SILVA, C. P. C.; FAVERO, A. C.; PURGATTO, E.; SHIGA, T. M.; REGINA, M. A. Composição físico-química de uvas para vinho em ciclos de verão e inverno. Revista Brasileira de Fruticultura, Jaboticabal, v. 32, n. 4, p. 1127-1137, 2010.

OLIVEIRA, J. E. M.; LOPES, P. R. C.; HAJI, F. N. P.; MOREIRA, A. N.; MIRANDA, J. R. Produção Integrada de Uva PI - Uva no Vale do São Francisco. In: ZAMBOLIM, L.; NASSER, L. C. B.; ANDRIGUETO, J. R.; TEIXEIRA, J. M.; FACHINELLO, J. C. (Org.). Produção integrada no Brasil. Brasília: MAPA, 2009. v. 1, p. 915-934.

SOUSA, J. S. I. Origens do vinhedo paulista. São Paulo: Obelisco, 1959. 319 p.

TONIETTO, J. O conceito de denominação de origem: uma opção para o desenvolvimento do setor vitivinícola brasileiro. Bento Gonçalves: EMBRAPA, 1993. 20 p.

TONIETTO, J. Experiências de desenvolvimento de indicações geográficas: vinhos da Indicação de Procedência Vale dos Vinhedos. In: LAGES, V.; LAGARES, L.; BRAGA, C. (Org.). Valorização de produtos com diferencial de qualidade e identidade: indicações geográficas e certificações para competitividade nos negócios. Brasília: Sebrae, 2006. p.155-176.

TONIETTO, J. ; ZANUS, M. C. Vins de qualité d'origine contrôlée au Brésil. In: WORLD CONGRESS OF VINE AND WINE, 30. 2007, Budapeste. Proceedings... Budapeste: OIV, 2007. p. 1-5. 